\title{
Oral Rehabilitation in a Child with Anodontia Case Report
}

\author{
Ileana Bledea ${ }^{1 *}$, Irina Totolici ${ }^{2}$ and Cristina Gabriela Puscasu ${ }^{3}$ \\ ${ }^{1}$ DMD in private Dentistry, Private Dental Clinique, Constanta Romania \\ ${ }^{2}$ Department ofPaediatric Dentistry, private dental Clinique, Constanta Romania \\ ${ }^{3}$ Department of Periodontology, Faculty of Dentistry, Constanta Romania
}

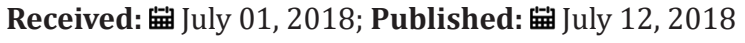

*Corresponding author: Ileana Bledea,DMD in private Dentistry Private Dental Clinique, Constanta Romania

\begin{abstract}
Anodontia is an inherited genetic disorder and is associated withectodermal dysplasia. Oral rehabilitation procedures are helping clinicians restore patients to better function and more esthetic outcomes than ever before. Oral rehabilitation is a difficult field in dentistry and especially in very young patients. It is a big problem to deal with children especially when you need to use dentures but is more delicate to use the implants in very young children. Due to the ectodermal anomaly the child has not just dental problems but also some general disturbances. This article deals with the procedure of total denture until the children will be able to receive implants for a better function.
\end{abstract}

Keywords: Oral Rehabilitation; Total denture; Anodontia; Ectodermal Dysplasia

\section{Introduction}

Ectodermal dysplasia is a rare inherited disorder characterized bydysplasia of at least two tissues of ectodermal origin [1,2]. The clinical features are well known and are based on congenital missing of temporary and permanent teeth, also thin, rare hair and hypoplastic skin. The incidence of this condition is 1:100000[3].

\section{Aim}

To present the major morpho-functional parameters affected by thisdevelopmental anomaly. Also, to mention the reduced possibilities to restore the dento-maxilar functionality in children with ectodermal dysplasia. The oral rehabilitation in children with anodontia of permanent teeth depends on the bone status and parents' financial status but also the interconnection between the pediatric dentist, the prosthodontist and the implantologist.

\section{Material and Method}

Clinical case of a6-year-old male patient clinically and radiologically diagnosed with anodontia in both maxillary and mandible and with the presence of only upper central incisors [4-21].The patient's gender is male and at the moment of his first presentation was 6 years old and a month. The child is the first born in the family. After the anamnesis we found out from his mother that the child didn't have the temporary teeth. The first and only erupted teeth were the two upper central incisors with absolute microdontia, but the shape is normal. In patients with partial anodontia teeth malformations are the most frequent dental findings: incisors and canines are often conical-shaped while primarily second molars, if present, are mostly affected by
taurodontism[4].The chief complaint was the phonation problem but also mastication and alimentation. The child cannot speak well at the school and has some esthetic problems like elder aspect due to the reduced height of the lower level of the face. The phonation was affected due to the missing of the temporary teeth and because of that, the tongue became slightly hypertrophic.The patients with ectodermal dysplasia present a soft, smooth, thin and dry skin[5]. Our patient presented with thin, dry and friable hair. The skin was thin and had no elasticity and the thermoregulation mechanism was affected. Other clinical elements of the ectodermal dysplasia were observed: his eyebrows and eyelashes were very thin and almost non-existent; the skin had an elderly aspect(Figures1 \& 2).

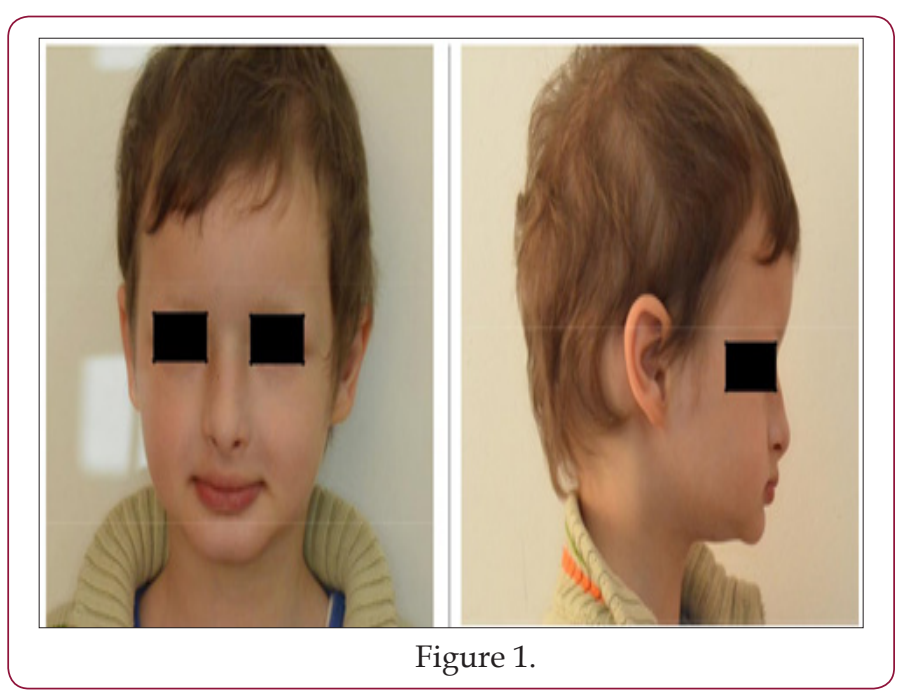




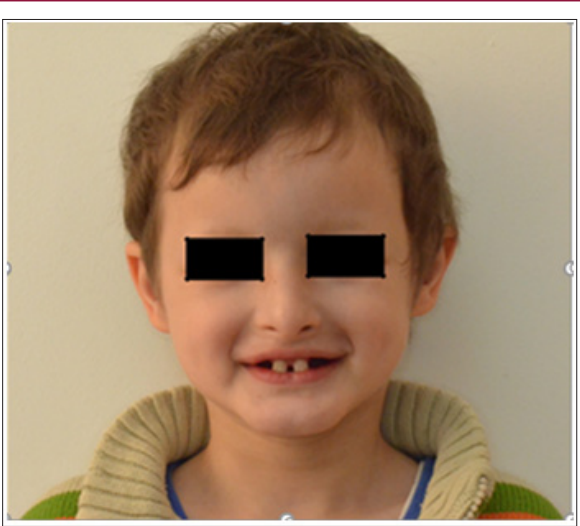

Figure 2.

In the photos we can observe the specific aspect of the reduced vertical dimension of the lower face height that is specifically to the total edentation of the mandible and maxilla.The intraoral examination revealed the edentulous alveolar ridge of the maxillary and the mandible. The maxillary had a very thin alveolar ridge and reduced height. The patient has large palate vault that could be used as an advantage for the stability of the upper partial denture. We also observed a large diastema between $[11,21]$.The mandible is total edentulous, and the problem is that both the bone and the alveolar ridge are thin and very low in height, so the stability of the lower denture will be reduced(Figures3 \& 4).

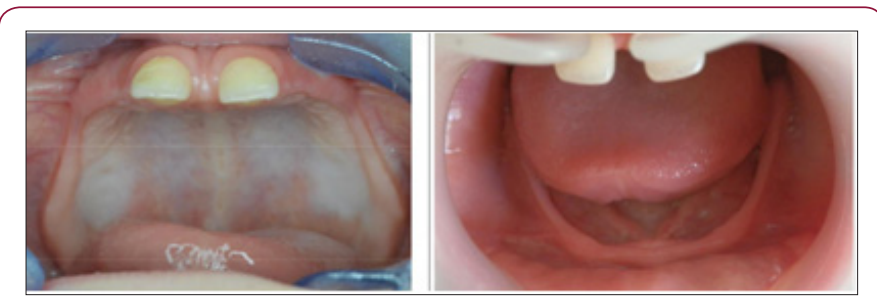

Figure 3.

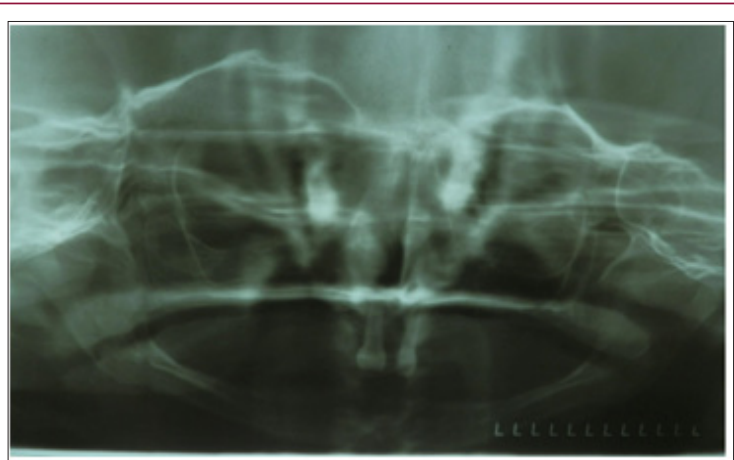

Figure 4 .

The panoramic radiographs revealed no temporary and no permanent teeth except the both central upper incisors, a thin and insufficient bone in maxillary and mandible. The bone quantity and quality are deficient.During the examination the child was afraid, and we couldn't find out if he suffered from other systemic diseases because the mother was not very implicated.In order to restore the functionality of the dento-maxillary system we decided to make a prosthetic rehabilitation with mobile dentures so that the patient could speak and eat in normal limits.Early prosthetic rehabilitation is an essential treatment because it is important from the functional, esthetic and psychological point of view [6,7]. In conformity with some study, the denture in children allows mandible and maxillary expansion and the expression of the growth-pattern [8].Having in view the patient's age and the clinical situation for the patient's functionality improvement of the dentomaxillary system we decided to start with two mobile dentures: one subtotal denture for the maxillary and one total denture for the mandible(Figure 5).Since the alveolar bone is dependent on the presence of the teeth, the denture reconstruction is more difficult in children with anodontia and ectodermal dysplasia[9].The preliminary impression was made with irreversible hydrocolloid to prepare the custom trays for better impression. In the second stage, we made an individual tray, and we took the impression in the individual tray [10].In order toestablitsh the maxillo-mandibular relations, to reconstruct the occlusion and to improve the vertical dimension of the lower face height, we made acrylic bases with wax rims(Figure 6).

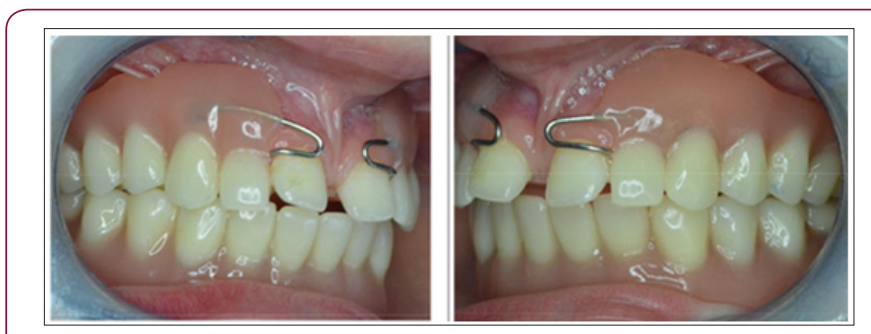

Figure 5.

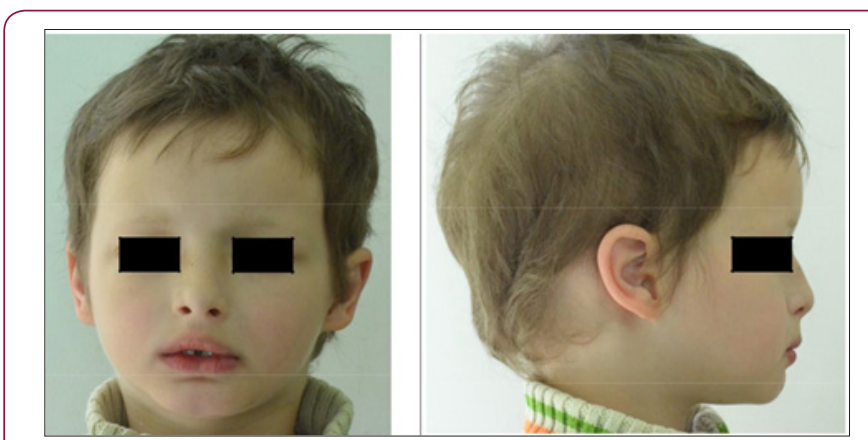

Figure 6.

As we can see the esthetic aspect of the patient's face and profile is improved due to the dentures. The child and mother received the information necessary to use the dentures.After the final insertion, both the child and mother were informed about the necessity of cleaning and the routine hygiene instruction for the dentures. Also, the patient was informed about the type of mastication, the importance that the food must be in small pieces and also that he must chew on both sides at the same time. In the first days we instructed him to consume a soft diet. The tongue will need a time to adapt to the narrow space, now reduced by the presence of the two dentures.As the dentures are worn the child must learn to speak and eat with them. Surprisingly the child was very happy with this oral rehabilitation and in a short period of time he managed well the phonation and chewing.We followed up the patient every 3 months to monitorize the growth and development of the bone and his accomodation to the new dentures.The children with ectodermal dysplasia have a poor alveolar bone development due to the absence of teeth as it could be observed in CBCT. 


\section{Results}

The child is now in a good esthetic, phonation and masticatory functionality do to the oral rehabilitation with mobile dentures in maxillary and mandible and we were happy to observe that he tolerated the dentures quite well(Figure 7).

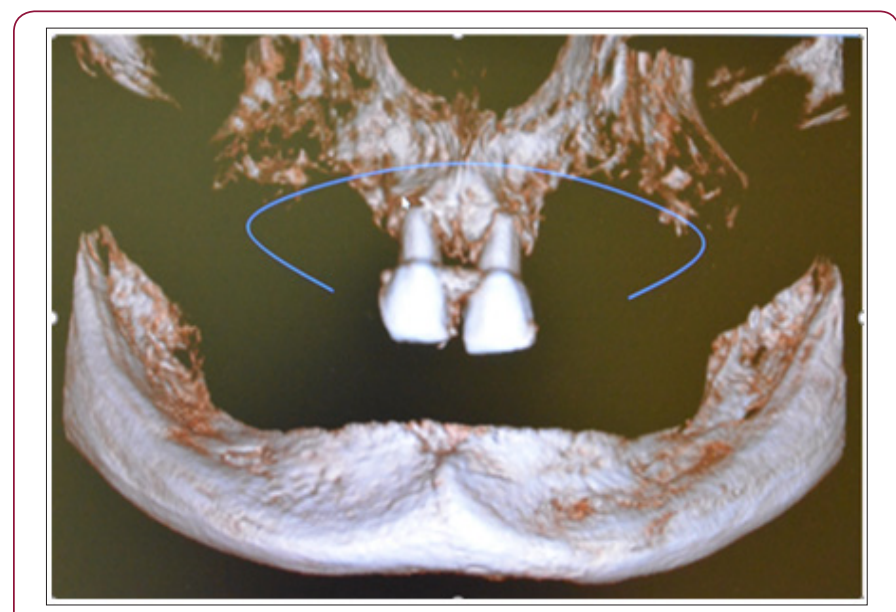

Figure 7.

\section{Discussion}

After a few years we will have to change the old dentures with new, bigger ones because of the natural growth of the bones which naturally occurs while the child advances in age. Because it is very difficult for a child to manage with dentures we decided, after a few years when the child will be able to support a surgical intervention to try osseous or subperiostal implants in order to change the mobile denture with a fixed one.Thus, we made a CBCT to examine the bone support. Unfortunately, after the bone measurements, we observed an insufficient bone for the implants. This low bone quantity is due to the absence of the temporary and permanent teeth buds.Is it obvious that the bone will not grow in height and so the osseous implants could be used with caution only in the interforamenianarea? Unfortunately, this patient will have to wear mobile dentures until new techniques in implantology will be developed.Inspired by the new technique of scan impression we think that in future it will be possible to make a fixed denture based on a scanned bone impression or using models from 3D printers based on quality CBCT. The denture could be be attached to the subperiosteal implant fixed with osteosynthesis screws(Figure 8).

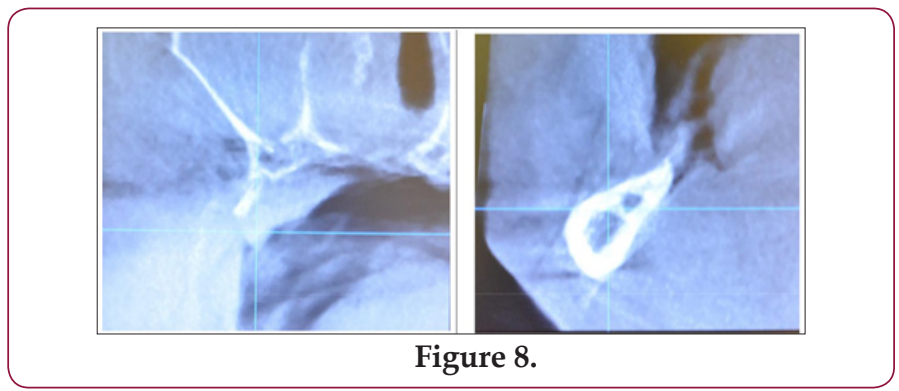

\section{Conclusion}

By the help of the dentures, the child has now a better esthetic and his fonatory and masticatory functions improved.It is more difficult to make dentures in the childhood period and there is a big difference between an alveolar edentulous ridge after extraction and the edentulous ridge in ectodermal dysplasia.

\section{References}

1. Clarke A (1987) Hypohidrotic ectodermal dysplasia. J Med Genet 24(11): 659-663.

2. FreireMaia N, Pinheiro M (1984) Ectodermal Dysplasias: A Clinical and Genetic Study. Alan R Liss 28(4): 1025-1026.

3. Nunn JH, Carter NE, Gillgross TJ, Hobson RS, Jepson NJ, et al. (2003) The interdisciplinary management of hypodontia: background and role of paediatric dentistry. Br Dent J 194(5): 245-251.

4. Bondarets N, Jones RM, Mc Donald F (2002) Analysis of facial growth in subjects with syndromic ectodermal dysplasia: a longitudinal analysis. OrthodCraniofac Res 5(2): 71-84.

5. Rajendran R (2006) Diseases of the skin. In: Shafer WG, Hine MK, Levy BM, Sivapathasundharam Rajendran Rand (Eds.). A text book of oral

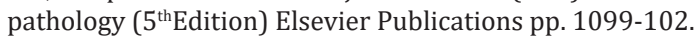

6. Pigno MA, Blackman RB, Cronin RJ, Edmund Cavazos (1996) Prosthodontic management ofectodermal dysplasia: a review of the literature. J Prosthet Dent 76(5): 541-545.

7. Kotsiomiti E, Kassa D, Kapari D (2007) Oligodontia and associated characteristics: assessment in view of prosthodontic rehabilitation. Eur J ProsthodontRestor 15(2): 55-60.

8. Bondarets N, Jones RM, McDonald F (2002) Analysis of facial growth in subjects with syndromic ectodermal dysplasia: a longitudinal analysis. OrthodCraniofac Res 5(2): 71-84.

9. Vieira KA, Teixeira MS, Guirado CG, Gaviao MB (2007) Prosthodontic treatment of hypohidrotic ectodermal dysplasia with compete anodontia: case report.Quintessence Int 38(1): 75-80.

10. Mehmet B, Ali Melih T, Nese A, Tamer T (2010) Ectodermal dysplazia with anodontia. A report of two cases. Eur J Dent 4(2): 215-222.
ISSN: 2574-1241

DOI: $10.26717 / B J S T R .2018 .06 .001392$

Ileana Bledea. Biomed J Sci \& Tech Res

(C) This work is licensed under Creative

Submission Link: https://biomedres.us/submit-manuscript.php

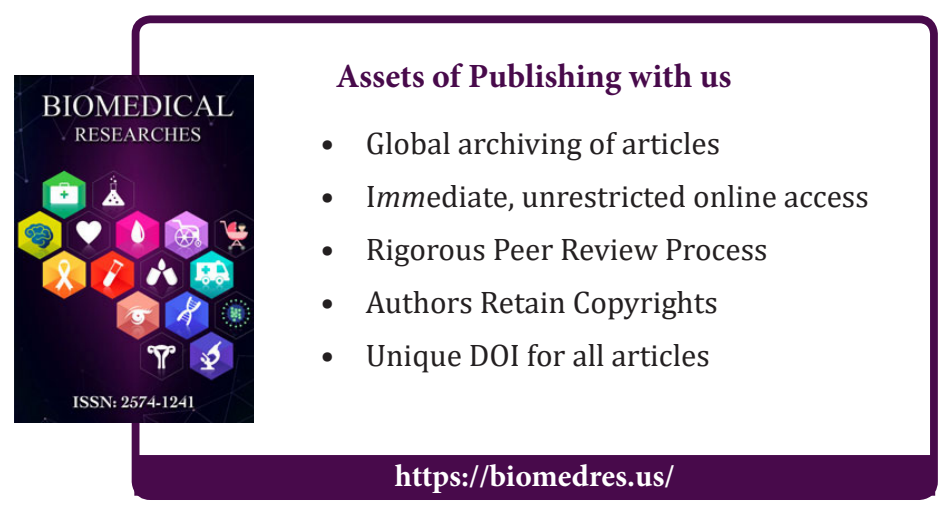

